\section{(A) Check for updates}

Cite this: Green Chem., 2021, 23. 3061

Received 30th November 2020

Accepted 31st March 2021

DOI: $10.1039 / \mathrm{dOgc0} 4058 \mathrm{~d}$

rsc.li/greenchem

\title{
Structural and molecular-weight-dependency in the formation of lignin nanoparticles from fractionated soft- and hardwood lignins $\uparrow$
}

\author{
levgen V. Pylypchuk, (D) *a Anastasia Riazanova, ${ }^{\text {b }}$ Mikael E. Lindström ${ }^{\mathrm{a}, \mathrm{b}}$ and \\ Olena Sevastyanova*a,b
}

\begin{abstract}
The use of lignin from forests as a renewable resource is a greener alternative to the petrochemical industry and accelerates the progress towards the development of more environmentally friendly industrial processes. A better understanding of the complexity of lignin as a raw material is necessary for creating new sustainable value chains, and a deeper understanding of the forces and interactions driving the self-assembly of lignin nanoparticles (LNPs) is required to create new, more advanced lignin nanomaterials. In the current study, "a library" of LNPs made from both softwood (spruce) and hardwood (eucalyptus) lignins was prepared utilizing green solvents-fractionated kraft lignins with narrow structural and molecular weight dispersity, and the LNPs were thoroughly characterized with respect to their size, shape, and surface properties. For both spruce and eucalyptus lignin fractions, the size of the LNPs decreased with increasing $M_{w}$ with a decreasing number of phenolic hydroxyls and an increasing number of aliphatic hydroxyl units in the lignin fraction. The diameter of the LNP's could be varied between 80 and $500 \mathrm{~nm}$, depending on the $M_{w}$ of the initial lignin and its concentration. The number of methoxy and phenolic groups in the aromatic ring, the aliphatic hydroxyls and $\beta-\mathrm{O}-4$ bonds in side chains in lignin fractions affect the morphology and surface structure of the LNPs to a significant degree. The LNP's with shapes ranging from doughnut-like structures to filled interconnected spheres were prepared, depending on the type of lignin phenylpropanoid units (botanical origin), concentration, and other properties of the lignin fractions. The identified strong dependence of the properties of the LNPs on the inherent properties of the lignin from which they were derived reveals that it is of crucial importance to select the appropriate starting lignin materials for the controlled design and synthesis of LNPs. This reduces costs for the subsequent purification and further processing of the LNPs, and prevents environmental pollution by minimizing the usage of resources. The obtained knowledge provides a clear guideline for the design of new biomass-based materials.
\end{abstract}

\section{Introduction}

Lignin is a natural aromatic polymer which is attracting attention due to its abundance and unique polymeric properties. ${ }^{1-3}$ Kraft lignin, obtained as a cheap byproduct of the paper pulp

\footnotetext{
${ }^{a}$ Division of Wood Chemistry and Pulp Technology, Department of Fiber and Polymer Technology, School of Chemistry, Biotechnology and Health, KTH Royal Institute of Technology, Teknikringen 56-58, 10044 Stockholm, Sweden.

E-mail: ievgenpy@kth.se, olena@kth.se; Tel: +46764090 812, +46767 762735

${ }^{b}$ Wallenberg Wood Science Center, Department of Fiber and Polymer Technology, School of Chemistry, Biotechnology and Health, KTH Royal Institute of Technology, Teknikringen 56-58, 10044 Stockholm, Sweden

$\dagger$ Electronic supplementary information (ESI) available: The nanoparticle labeling; properties of lignin fractions; full-range SEM micrographs of LNPs obtained at different lignin concentrations; PDI of LNPs; LNPs zeta-potential data obtained at different lignin concentrations; carboxylic acid contents for each lignin fraction; TEM micrographs of LNPs; numbers of S and $\mathrm{G}$ units in each lignin fraction. See DOI: 10.1039/d0gc04058d
}

industry, is potentially available in large quantities, ${ }^{4}$ while the manufacturing costs for nanoparticles obtained from lignin is estimated to be approximately 1000 USD per t. ${ }^{5}$ Lignin is being upgraded and used in numerous materials for many applications, e.g. in the development of thermosets, ${ }^{6,7}$ polymer blends $^{8}$ and packaging, ${ }^{9,10}$ and as an active component and source in hybrid composites, ${ }^{11}$ carbons, ${ }^{12}$ adsorbents, ${ }^{13}$ etc. Special attention is being devoted to lignin nanoparticles, which are environmentally benign ${ }^{14}$ and have been tested for loading in biomedicines, ${ }^{15}$ as Pickering emulsions, ${ }^{16}$ and for virus agglomeration, ${ }^{17}$ etc. The main applications of lignin nanoparticles have been thoroughly reviewed by Sipponen and Österberg. . $^{15,18}$

LNPs have been prepared utilizing their self-assembly properties. ${ }^{19}$ In general, the structure depends on the source of the lignin, the selection of the solvent, and the type of noncovalent interactions, etc. LNPs grow by controlled nucleationgrowth mechanism, ${ }^{20}$ where the lignin molecules with a high 
$M_{\mathrm{w}}$ form the initial critical nuclei. In most cases, the size of the LNPs is dependent on the initial concentration of the lignin.

Lignin is, however, a heterogeneous substance, and it is not always possible to establish a relationship between the structure and the properties of the material. To cope with the heterogeneity and to obtain a better understanding of the structure-properties relationship in a lignin-based material, various fractionation techniques have been suggested, such as membrane ultrafiltration, ${ }^{21-24}$ selective precipitation, ${ }^{25,26}$ and solvent fractionation. ${ }^{27,28}$

LNPs have recently been prepared from ethanol-fractionated kraft hardwood ${ }^{29}$ and organosolv ${ }^{30,31}$ lignins. Ma, ${ }^{29,32}$ and Pang $^{33}$ showed that the size of LNPs is reversibly proportional to the $M_{\mathrm{w}}$ of lignin. However, the influence of the initial lignin concentration on the properties of the final LNPs was not investigated in these works. Wang, ${ }^{34}$ on the other hand, showed that initial lignin concentration is crucial to the morphology of LNPs. The mechanism of the formation of LNPs was linked to hydrophilic-hydrophobic interactions. ${ }^{35}$ However, no direct linkage between the lignin chemical structure and the size of LNPs was demonstrated, probably because the selected fractionation methods did not result in extensive separation between low and medium molecular weights ${ }^{35}$ and did not provide a separation of distinct populations of lignin molecules. No comparative studies between lignin of different origin were provided in the abovementioned papers.

In the current study, we have used a method of lignin fractionation which allows for the fine-tuning of lignin properties, such as hydrophobicity, the content of phenolic and aliphatic units, $M_{\mathrm{w}}$, and the number of S- and G-units.

Since the formation of LNPs seems to be driven by $\pi-\pi$ interactions and by hydrogen bonding between phenolic rings of lignin, ${ }^{36-38}$ the number of phenolic and aliphatic units should affect the size of LNPs. In the present work, we have applied a 4-step green fractionation approach, leading to the separation of different populations of lignin molecules with respect to their $M_{\mathrm{w}}$ and the number of aromatic and aliphatic units, to prepare LNPs from well-characterized lignin materials. We have also varied the initial lignin concentration for each lignin fraction and have attempted to understand the impact on the size, shape, and surface charge of the LNPs of factors such as the lignin origin, the $M_{\mathrm{w}}$, the number of $\mathrm{S} / \mathrm{G}$ units, the amounts of phenolic and aliphatic hydroxyl groups, $\beta-\mathrm{O}-4$ bonds and the content of carbohydrate impurities.

This information allowed us to link the molecular structure of lignin to the properties of resulting LNPs and to control the synthesis and fine-tuning of the properties of LNPs to suit their intended uses. Such a strong dependence of the properties of the nanoparticles on the inherent properties of the lignin from which they were derived allows for the selection of the most suitable lignin fractions to prepare LNPs with the desired properties, thus reducing costs for the purification and further processing of LNPs. Also, the application of the green solvents for the lignin fractionation during the preparation of the LNPs prevents environmental pollution by minimizing the usage of unnecessary resources.

\section{Materials and methods}

\section{Materials}

Kraft lignins from hardwood (Rose Gum Eucalyptus Grandis) and softwood (Norway Spruce) were extracted from the corresponding black liquors according to the LignoBoost process. Ultrapure water (18.2 $\mathrm{M} \Omega \mathrm{cm})$; ethyl acetate, ethanol (96\%), methanol, acetone (all from VWR chemicals); and $0.45 \mu \mathrm{m}$ membrane filters (Fisherbrand, PTFE) were used.

\section{Lignin fractionation}

The solvent fractionation of kraft lignin has been described elsewhere. ${ }^{27}$ Briefly, $20 \mathrm{~g}$ of lignin powder was extracted with $200 \mathrm{ml}$ of solvent for 2 hours at room temperature. The soluble fraction was decanted, the solvent was evaporated and the lignin material was freeze-dried for 3 days. The insoluble fraction was suspended in the next solvent and the next extraction step was performed similarly. The solvent order was: ethyl acetate (EtOAc) (N1), ethanol (EtOH) (N2), methanol (MeOH) (N3), and acetone (N4). The residual lignin fraction insoluble in these solvents was numbered as fraction N5. The fractionated lignins were named according to their botanical origin and the number of the fractionation step by which they were derived. For instance, the eucalyptus and spruce lignin fractions obtained in the first stage by dissolution in EtOAc have the abbreviations EL1 and SL1, respectively. The full characteristics of the lignin fractions have been reported previously ${ }^{6}$ and are available in Tables S2 and S3 (ESI $\dagger$ ).

\section{Size-exclusion chromatography (SEC)}

The molecular weights of the lignins were determined utilizing SEC, according to the protocol reported by Tagami et al. (2016). ${ }^{39}$

\section{Preparation of LNPs}

The LNPs were prepared by the antisolvent precipitation approach. The lignin from each fraction was first dissolved in acetone : water $(4: 1, \mathrm{v} / \mathrm{v})$ to give a solution with a lignin concentration in the range of $0.1-6 \mathrm{mg} \mathrm{ml}^{-1}$, and the solution was then filtered through a $0.45 \mu \mathrm{m}$ PTFE filter to remove undissolved material and possible aggregates. The filters after filtering were weighted and the lignin concentration was normalized on the amount of lignin adsorbed on the filter. The fractions show different content of undissolved lignin, in the range of $0.5-1.3 \mathrm{wt} \%$. Deionized water $(4 \mathrm{ml})$ was then added dropwise under moderate stirring to $1 \mathrm{ml}$ of the lignin solution in acetone:water, and the solution was stirred until the acetone had evaporated. The NPs from the EL1-4 and SL1-4 fractions were obtained. The sample marking is presented in Table S1 (ESI†).

\section{DLS}

The zeta potential, average size, and size distribution of the nanoparticles in the different LNPs "as prepared", were determined using a Zetasizer Nano ZS instrument (MalvernPananalytical, Malvern, UK) at $25^{\circ} \mathrm{C}$. 
TEM

For the TEM studies, a Hitachi HT7700 series instrument (Hitachi, Japan) was used with an accelerating voltage of 100.0 $\mathrm{kV}$ and an emission current of $8.0 \mu \mathrm{A}$. Samples were prepared as follows: $5 \mu \mathrm{l}$ of an LNP suspension $\left(0.2 \mathrm{mg} \mathrm{ml}^{-1}\right)$ was dropcast onto a 200-mesh copper grid (Ted Pella Inc., USA; prod No 01800-F) and dried in air for $30 \mathrm{~min}$.

\section{SEM}

An S-4800 microscope was used (S-4800 Hitachi, Japan). Samples were drop-cast on a silicon wafer for $30 \mathrm{~min}$ and sputter-coated with a $2 \mathrm{~nm}$ layer of Pt-Pd alloy.

\section{Results and discussion}

The main purpose of this study was to investigate how the $M_{\mathrm{w}}$ and chemical functionality of lignin sources affect the size, shape, and other properties of the LNPs. The kraft lignins from spruce and eucalyptus used in this study were selected due to their availability and well-established analytical methods were used to characterize their properties, including molecular weight, chemical composition, number of functional groups, and inter-unit linkages. To vary the lignin functionality and to avoid both the natural lignin heterogeneity and the heterogeneity induced by the kraft pulping process, we have applied the solvent fractionation approach, ${ }^{27}$ a reproducible method of obtaining lignin fractions with $M_{\mathrm{w}}$ ranging from 900 to 20000 $\mathrm{Da}$ and PDI values lower than that of the initial lignin. ${ }^{6}$ Five lignin samples were obtained from spruce (SL1-SL5) and five from eucalyptus (EL1-EL5) kraft lignin. The low- $M_{\mathrm{w}}$ lignin fractions (EL-1, EL2, and SL1, SL-2), contained the largest number of phenolic hydroxyls ( $\mathrm{Ph}-\mathrm{OH})$ and the lowest number of aliphatic hydroxyls (Aliph-OH), as shown in Fig. 1a and b. The lignin fractions (EL5 and SL5) that were not soluble in any of the solvents contained the lowest number of $\mathrm{Ph}-\mathrm{OH}$ units, and these fractions had the highest content of carbohydrate impurities, usually as lignin-carbohydrate complexes (LCC). ${ }^{24}$ The $M_{\mathrm{w}}$, functional group content, PDI, and content of carbohydrates, of the different fractions, are given in Tables S2 and S3.†
The effect impact of the molecular weight of the lignin on the size of LNPs

The size of LNPs decreased with increasing the $M_{\mathrm{w}}$ of the fraction for both eucalyptus (Fig. 1a) and spruce (Fig. 1b) LNPs. The fractions with the lowest $M_{\mathrm{w}}$, EL1 and SL1, gave the largest LNPs, with diameters of 199 and $173 \mathrm{~nm}$ respectively (Fig. 1a and b); the higher- $M_{\mathrm{w}}$ fractions, such as EL4 and SL4, gave smaller LNPs, with diameters of 100 and $98 \mathrm{~nm}$ respectively. This trend was found for initial lignin concentrations between 1 and $6 \mathrm{mg} \mathrm{ml}^{-1}$ (Fig. 2a and c).

\section{The effect of the initial lignin concentration on the size and charge of the LNPS}

It has been reported in the literature for non-fractionated kraft lignins that the size of LNPs is proportional to the initial lignin polymer concentration, ${ }^{14,19,37,38}$ but the size of LNPs obtained from fractionated lignins has not yet been reported.

As expected, the diameter of LNPs increased with increasing lignin concentration for all the lignin fractions, both spruce and eucalyptus in the lignin concentration range of 1-6 $\mathrm{mg} \mathrm{ml}^{-1}$ (Fig. 2a and c), and the concentration of $6 \mathrm{mg} \mathrm{ml}^{-1}$ shows this trend clearly (Fig. $2 \mathrm{~b}$ and d). For the low- $M_{\mathrm{w}}$ lignin fractions, SL1 and EL1, nanoparticles with a diameter less than $200 \mathrm{~nm}$ were obtained at an initial lignin concentration of $1 \mathrm{mg} \mathrm{ml}^{-1}$, while nanoparticles with a diameter of around $500 \mathrm{~nm}$ have been prepared from the same fractions, with an initial lignin concentration of $6 \mathrm{mg} \mathrm{ml}^{-1}$. The size for LNPs precipitated at a lignin concentration of $0.1 \mathrm{mg} \mathrm{ml} \mathrm{m}^{-1}$ deviated from the trend, since they were larger than the LNPs precipitated at $1 \mathrm{mg} \mathrm{ml}^{-1}$. Also, the eucalyptus LNPs prepared at $0.1 \mathrm{mg} \mathrm{ml}^{-1}$ had a polydispersity greater than that of all the LNPs prepared at lignin concentrations 1 and $2 \mathrm{mg} \mathrm{ml}^{-1}$ (Fig. 3). Such a high polydispersity of LNPs precipitated at $0.1 \mathrm{mg} \mathrm{ml}^{-1}$ could be due to the low effective concentration of the polymer, reducing the ability of lignin molecules to interact and to form LNPs. Unreacted polymer and its aggregates would disturb the DLS measurement, resulting in a high polydispersity value. This is supported by SEM data, where a relatively large amount of unreacted polymer aggregates was observed for LNPs synthesized at $0.1 \mathrm{mg} \mathrm{ml}^{-1}$ (Fig. 4, 5, and S1 and $\mathrm{S} 2 \dagger$ ).
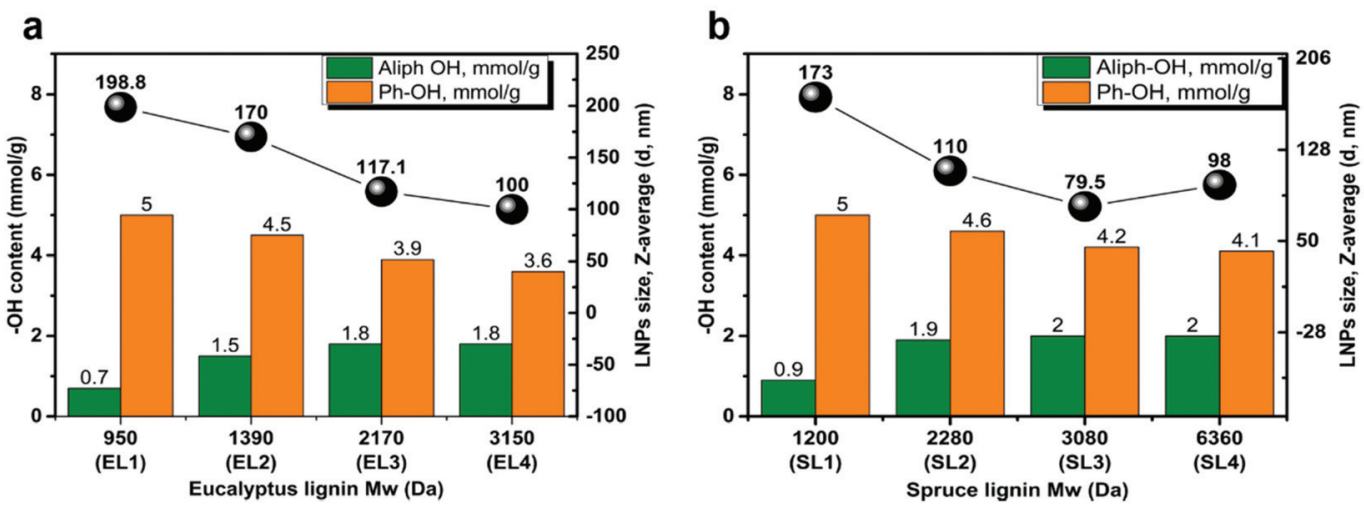

Fig. 1 The diameter of LNPs as a function of $M_{w}$ and the contents of $\mathrm{Ph}-\mathrm{OH}$ and Aliph-OH in the corresponding lignin fractions for (a) eucalyptus lignin; (b) spruce lignin. The LNPs were obtained at a starting lignin concentration of $1 \mathrm{mg} \mathrm{ml}^{-1}$. 


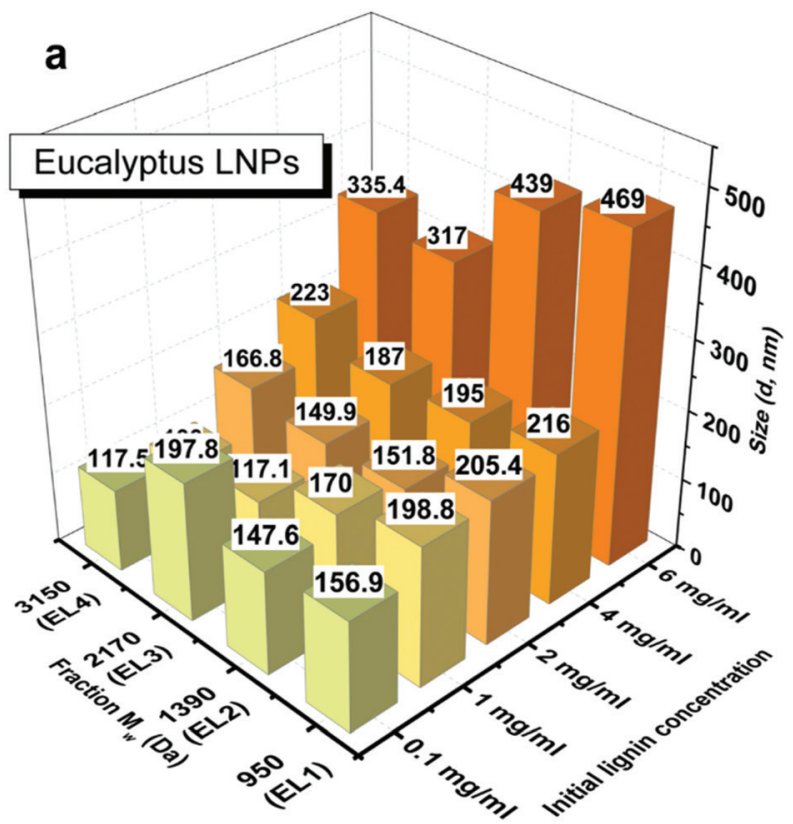

\section{b}
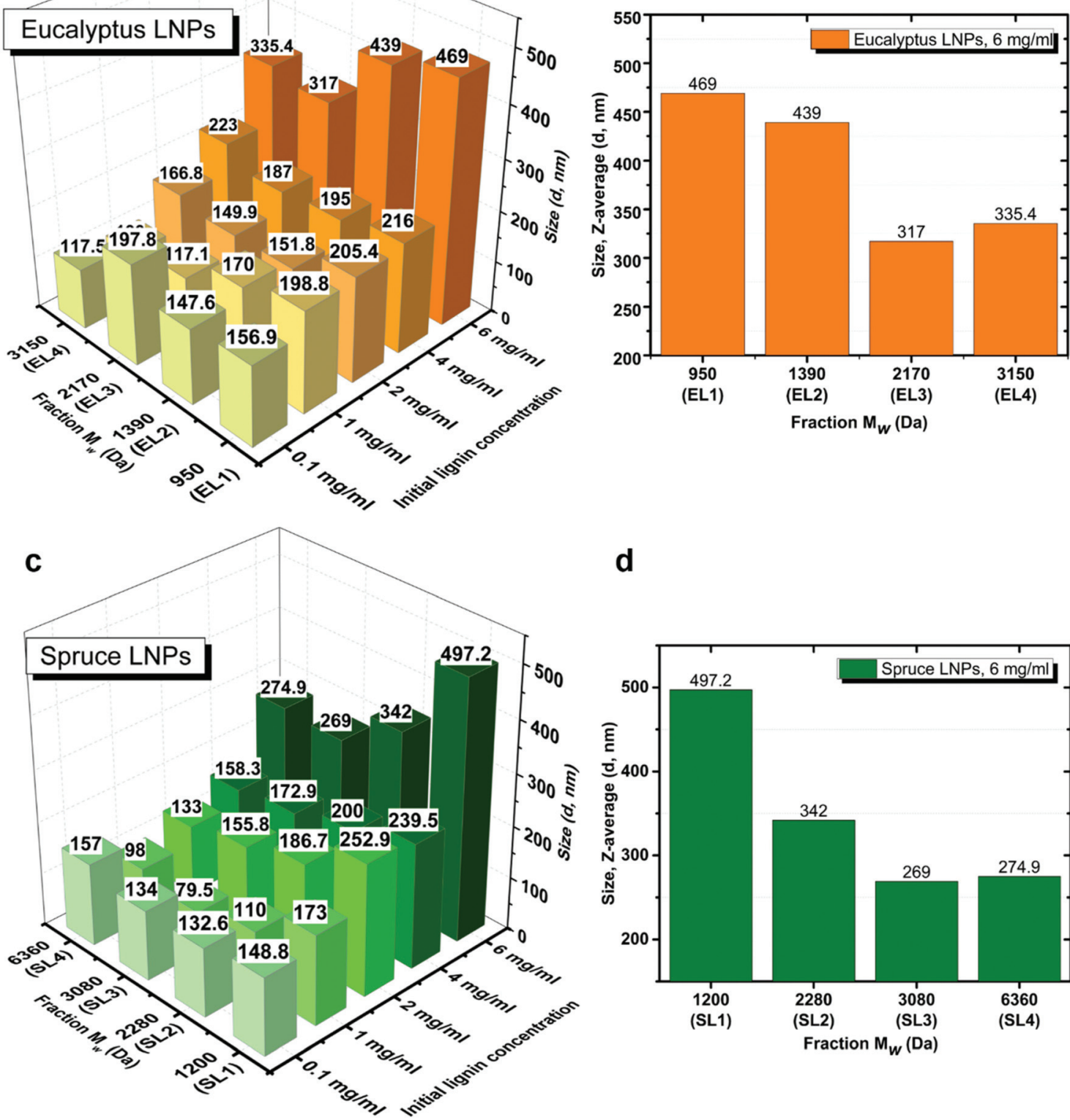

d

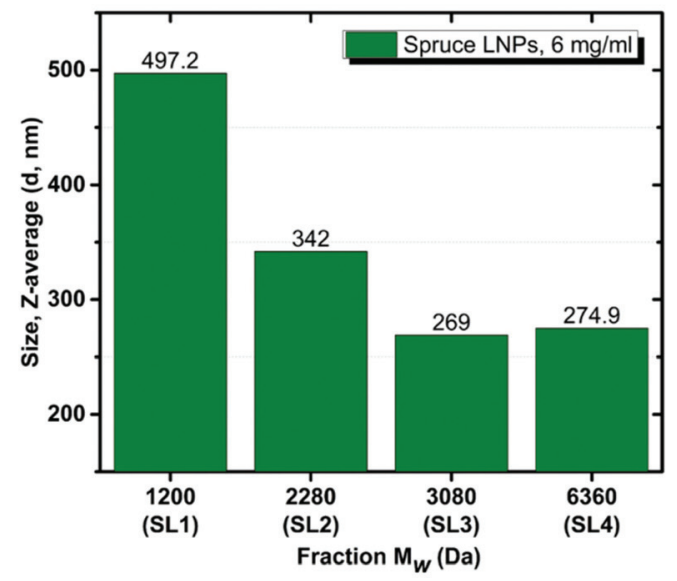

Fig. 2 Z-Average size $(d, \mathrm{~nm})$ of LNPs obtained from eucalyptus (a) and spruce (c) lignin fractions at initial lignin concentrations between 0.1 and $6 \mathrm{mg} \mathrm{ml}^{-1}$. The size trend for LNPs synthesized at $6 \mathrm{mg} \mathrm{ml}^{-1}$ from eucalyptus (b) and spruce (d) lignin.

The PDI values of lignin nanoparticles from both spruce and eucalyptus kraft lignin obtained at initial lignin concentrations of $0.1,1,2,4$, and $6 \mathrm{mg} \mathrm{ml}^{-1}$ are shown in Fig. 3a-c and Fig. S3.† Following the trend in Fig. 3a, one can conclude that the larger LNP size is associated with larger PDI and LNPs with diameter below $200 \mathrm{~nm}$ possessing the lowest PDI. The most heterogeneously sized spruce LNP (Fig. 3c) was obtained with an initial lignin concentration of $6 \mathrm{mg} \mathrm{ml}^{-1}$, whereas the most heterogeneous eucalyptus (Fig. $3 \mathrm{~b}$ ) was obtained with a lignin concentration of $0.1 \mathrm{mg} \mathrm{ml}{ }^{-1}$. This polydispersity seemed to be due to the presence of a large amount of unreacted polymer in the sample. The high PDI for the sample prepared at $6 \mathrm{mg} \mathrm{ml}^{-1}$ was due to a bimodal distribution with peak diameters at $100 \mathrm{~nm}$ and above $400 \mathrm{~nm}$ (Fig. 4, 5 and S1 and $\mathrm{S} 2 \dagger)$. For the eucalyptus lignin, the optimum initial concentration of lignin for the preparation of a homogeneous LNP by antisolvent precipitation was between 2 and $4 \mathrm{mg} \mathrm{ml}^{-1}$. For the spruce lignin, the optimum concentration was around $2 \mathrm{mg} \mathrm{ml}^{-1}$, regardless of the $M_{\mathrm{w}}$ of the lignin.

Zeta-potentials of LNPs obtained from eucalyptus and spruce lignin are shown in Fig. S4. $\dagger$ In general, spruce LNPs have a higher zeta potential than eucalyptus LNPs. It was concluded that the smaller the size of LNP, the higher is the zeta potential, i.e. the charge density is higher on smaller particles. 
a
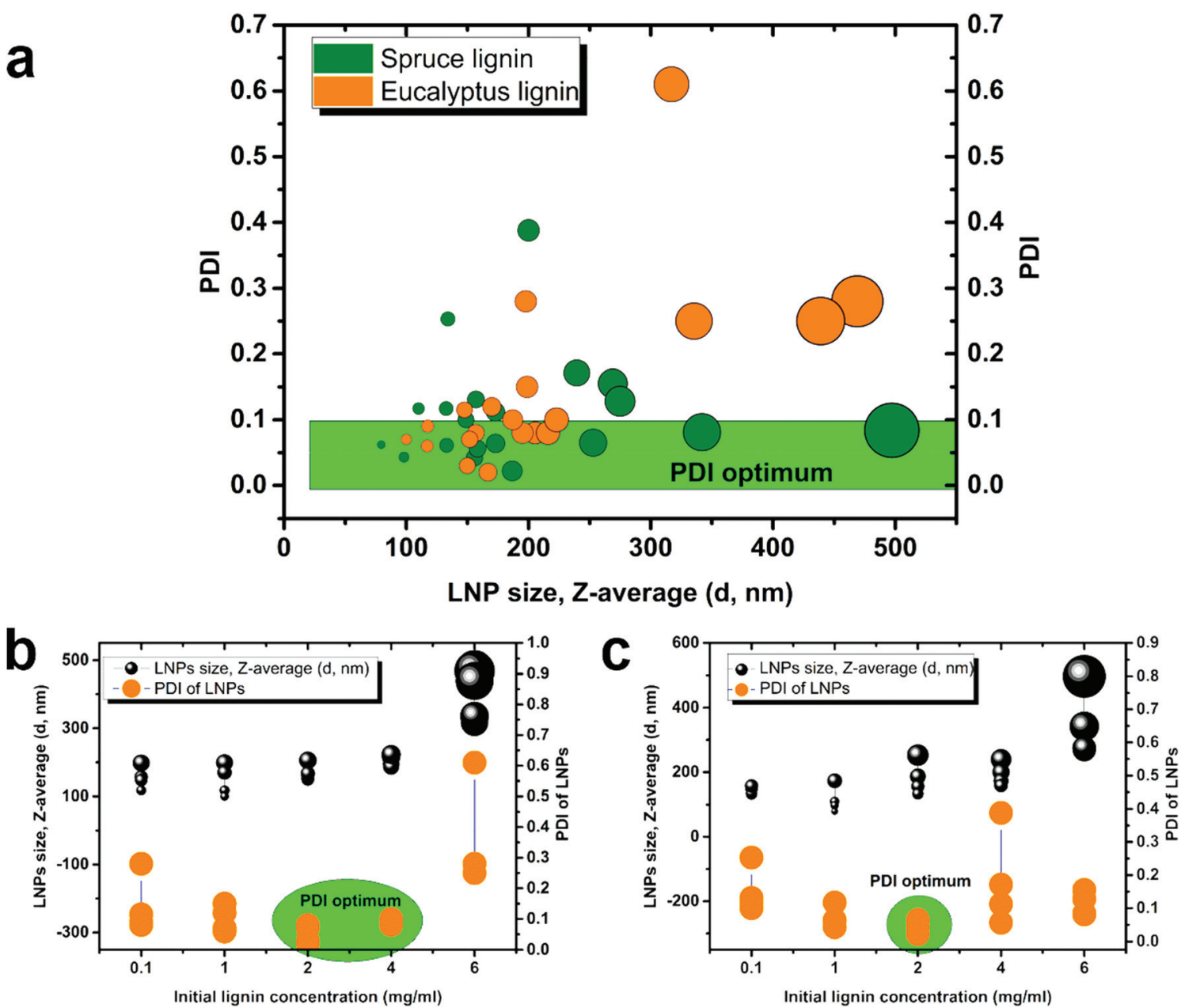

Fig. 3 Mixed data for PDI of the LNPs obtained from eucalyptus and spruce lignin vs. LNP size (a) and the PDI vs. concentration for eucalyptus LNPs (b) and spruce LNPs (c) at initial lignin concentrations between 0.1 and $6 \mathrm{mg} \mathrm{ml}^{-1}$. The size of black circles is proportional to LNPs size.

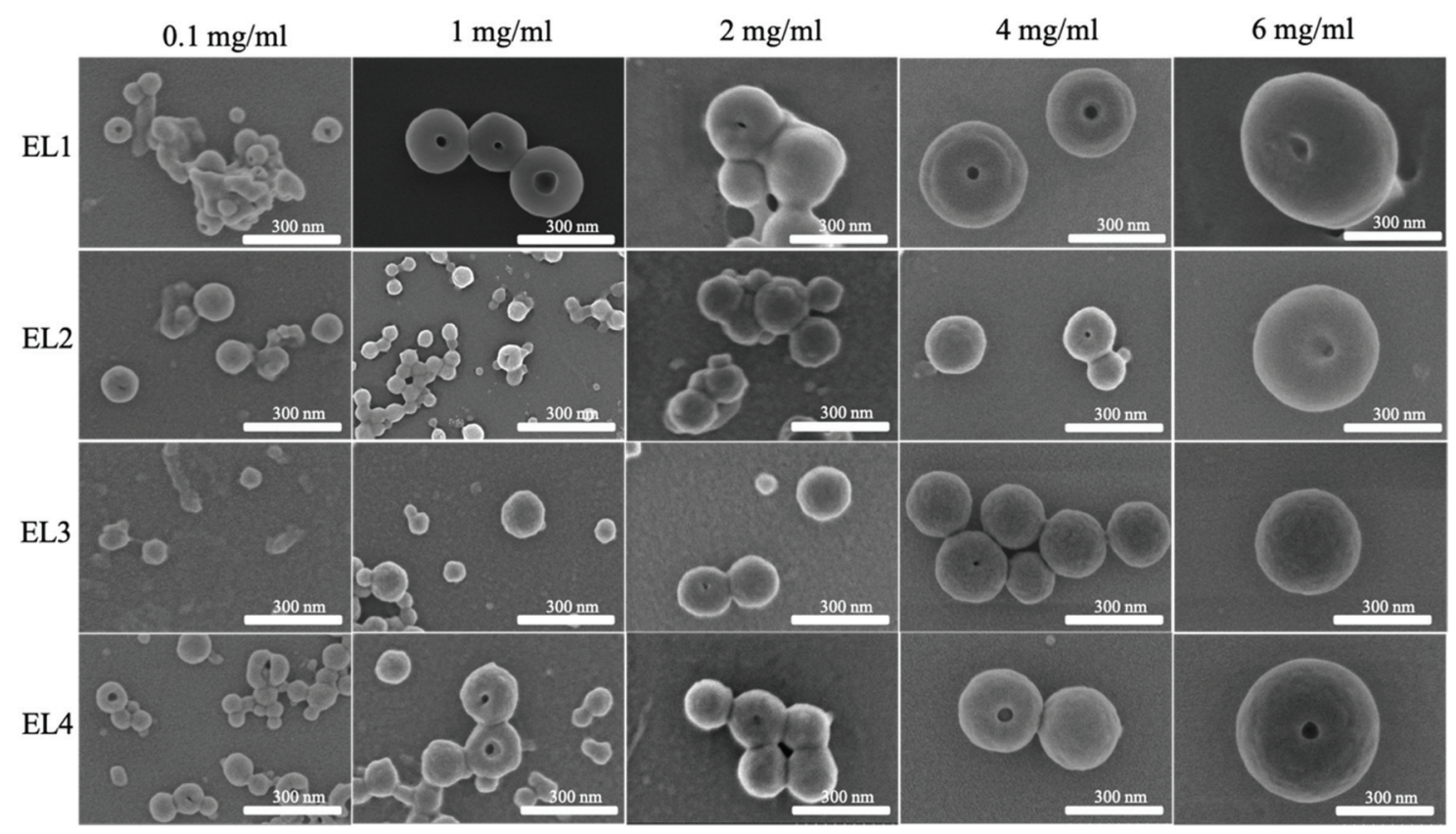

Fig. 4 SEM images of LNPs obtained from EL1-4 fractions. 


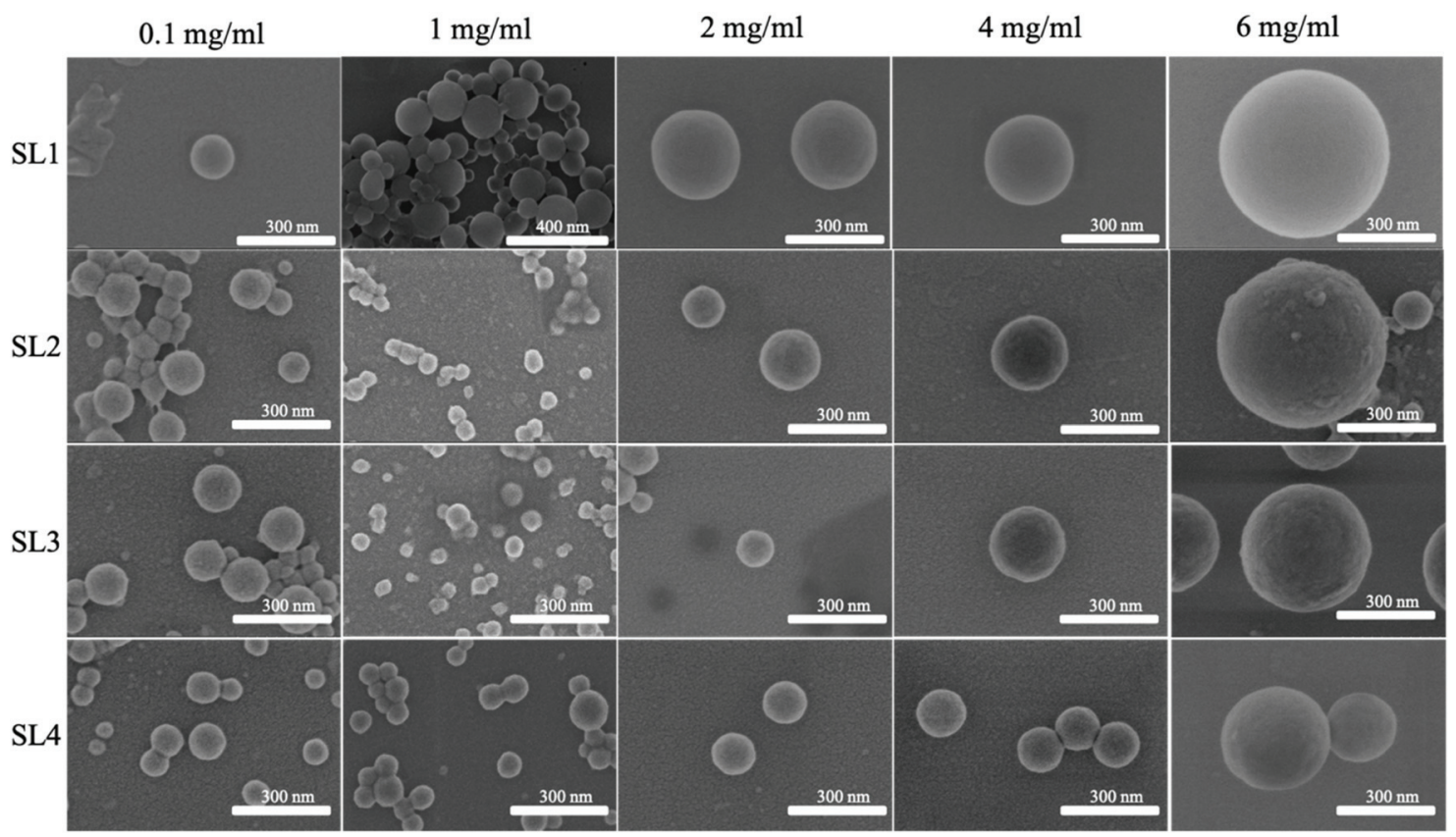

Fig. 5 SEM images of LNPs obtained from SL1-4 fractions.

\section{Morphology of the LNPs}

The dependence of the shape of the LNPs on the concentration and of the corresponding spruce and eucalyptus lignin fractions is shown in the SEM images in Fig. 4 and 5 respectively. More detailed SEM images of the LNP ensembles are presented in Fig. S1 and S2. $\dagger$

In lignin nanoparticles derived from the eucalyptus EL1-2 lignin fractions, SEM micrographs revealed spherical particles, doughnut-like nanostructures ( $30 \%)$, and sphere-with-a-hole particles. The EL3 fraction gave only spherical LNPs only, and at high initial lignin concentrations, holes, or dimples were observed in the spheres (Fig. S1 $\dagger$ ).

The LNPs from the spruce SL1-4 lignin fractions consisted of spherical particles, the size increasing with increasing lignin concentration (Fig. S2 $\dagger$ ). The inner structure of the LNPs differed from that of the SL1-4 fractions, as shown by TEM in Fig. S5. $\dagger$ For both eucalyptus and spruce, the LNPS obtained at $1 \mathrm{mg} \mathrm{ml}^{-1}$ were more separated, than the LNPs obtained at higher concentrations with more interlinkages, in agreement with literature data. ${ }^{18}$ The core-shell structure of the SL fractions resembles the amphiphilic behavior of the lignin molecules, where the hydrophobic regions form the core. Using liquid-state NMR, Pylypchuk et $a .^{40}$ have shown that the core of hollow LPNs consists of hydrophobic aliphatic units of lignin. The interconnections between LNPs are formed by the hydrophilic residues and such interactions were seen on the TEM images of all the LNPs (Fig. S5 $\dagger$ ).

\section{Concentration-dependence of the size of the LNPs within a single fraction}

It was shown that the size of the nanoparticles is proportional to the initial lignin concentration, but it was interesting to investigate the trend within a single fraction.
It is possible to distinguish two groups of LNPs: LNPS obtained from low- $M_{\mathrm{w}}$ SL/EL1-2 fractions (Fig. 6) and LNPS obtained from high- $M_{\mathrm{w}}$ SL/EL3-4 fractions (Fig. 7). In the first group, the particle size increases by roughly $\sim 30 \%$ in the concentration range of $0.1-4.0 \mathrm{mg} \mathrm{ml}{ }^{-1}$. At a concentration of $6 \mathrm{mg} \mathrm{ml}^{-1}$, the average particle size increases by $\sim 200 \%$, suggesting that some critical concentration governs the mechanism of formation of LNPs. For LNPs from the EL1-2 fractions (Fig. 6a and c), an increase in zeta-potential with increasing initial lignin concentration was observed, indicating a decrease in charge density on the LNPs surface. The same was true for LNPs from the SL1-2 fractions (Fig. 6b and d), except the LNPs obtained at $1 \mathrm{mg} \mathrm{ml} \mathrm{ml}^{-1}$, where the zeta-potential was the lowest, indicating that these were highly surface-charged nanoparticles. The high surface charge of LNPs is associated with the presence of carboxylic groups on their surface, and this is correlating with acidic groups content in lignin (Fig. S6†).

For the LNPs synthesized from high- $M_{\mathrm{w}}$ fractions SL/EL3-4, the increase in particle size with increasing of lignin concentration was more gradual, with no evident concentration threshold (Fig. 7a-d).

\section{The relationship between the size of LNPs and the number of $\mathrm{Ph}-\mathrm{OH}$ and Aliph-OH groups in the lignin fraction}

The size of the LNPs seems to correlate with the number of functional units in the corresponding lignin fraction (Fig. 1). Such a correlation in the case of $\mathrm{Ph}-\mathrm{OH}$ groups seems logical since the phenolic units in lignin are considered to be the main groups responsible for LNP formation (via hydrogen bonding and $\pi-\pi$ interactions). ${ }^{36-38}$

In both eucalyptus and spruce lignins, the number of aliphatic groups increases with increasing $M_{\mathrm{w}}$. The smaller 
a

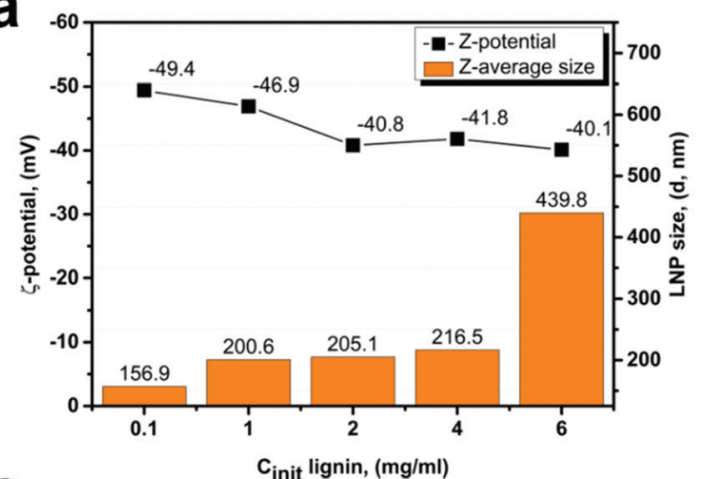

C

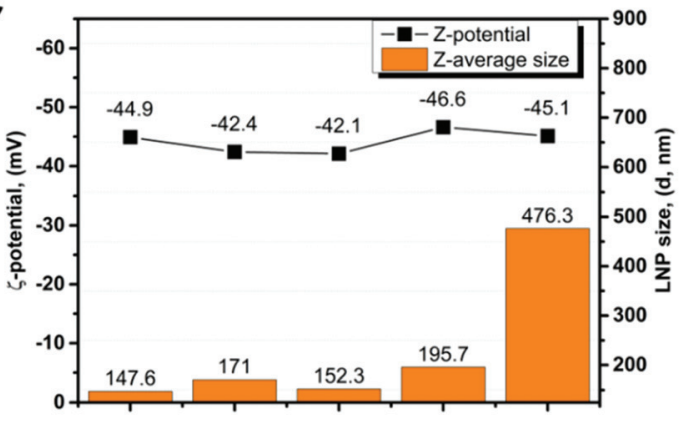

$C_{\text {init }}$ lignin, (mg/ml) b

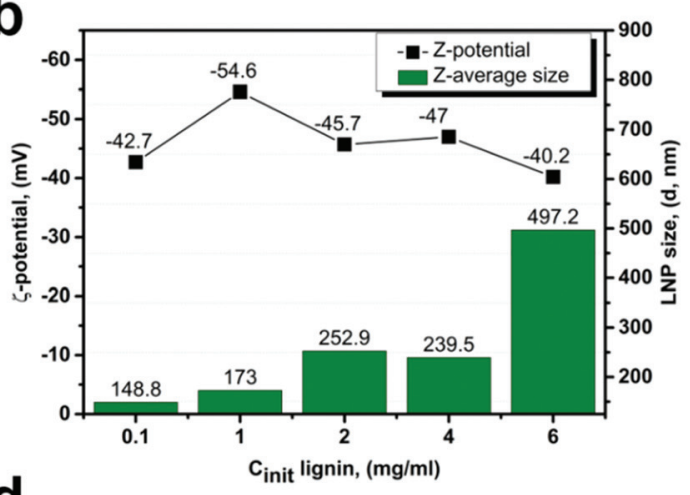

d

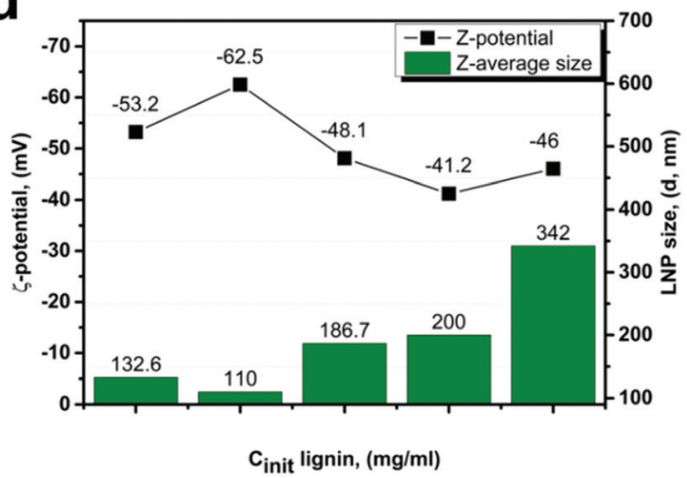

Fig. 6 Average size $(d, \mathrm{~nm})$ and zeta potential $(\mathrm{mV})$ of LNPs derived from EL1-2 (a and b) and SL1-2 (c and d) fractions at different initial lignin concentrations.

a

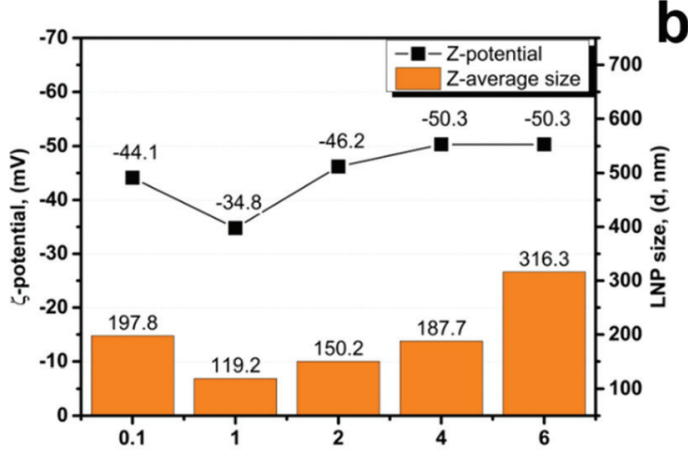

C

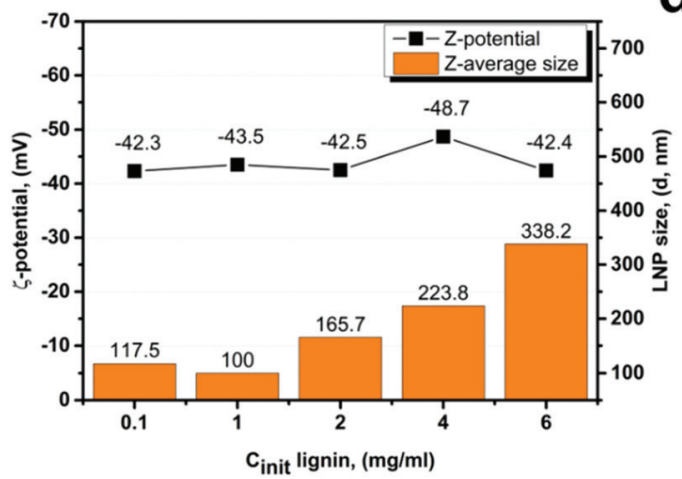

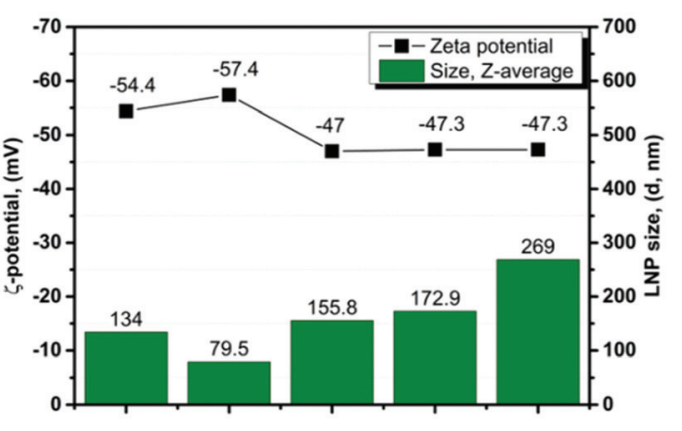

$\mathrm{C}_{\text {init }}$ lignin, ( $\left.\mathrm{mg} / \mathrm{ml}\right)$

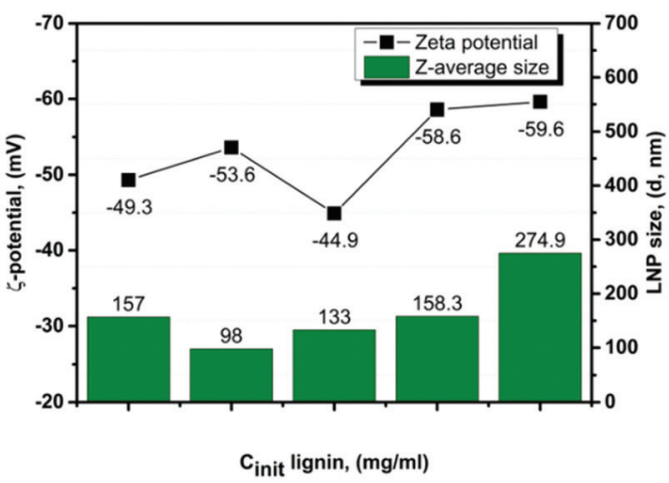

Fig. 7 Average size $(d, \mathrm{~nm})$ and zeta potential $(\mathrm{mV})$ of LNPs derived from EL3-4 (a and b), and SL3-4 (c and d) fractions at different initial lignin concentrations. 
number of aliphatic hydroxyls in low $M_{\mathrm{w}}$ fractions of lignin can be explained by a retro-aldol reaction during the kraft process, as proposed by Giummarella et al. ${ }^{41,42}$ Fig. 1 shows that the size of LNPs is the opposite, decreasing with an increasing number of Aliph-OH, even though the lignin $M_{\mathrm{w}}$ is increasing. The largest LNPs with a diameter of $c a .200 \mathrm{~nm}$ were obtained from the EL1 and SL1 fractions, having the lowest contents of aliphatic OH-groups (Fig. 1a and b).

The smaller size of LNPs from the SL2-4 and EL2-4 fractions can be explained by the participation of aliphatic hydroxyls in the formation of strong intramolecular hydrogen bonds. It has been previously reported ${ }^{43}$ that the degree of lignin clustering in a solvent is proportional to the aliphatic content and that this limits lignin solubility. The ability of lignin molecules to form non-covalent bonds with other lignin molecules is limited, resulting in smaller LNPs.

The relationship between the size of LNPs and the content of carbohydrates and $\beta-\mathrm{O}-4$ bonds in the lignin fraction

The low- $M_{\mathrm{w}}$ fractions of spruce and eucalyptus lignin contain fewer aliphatic side chains due to a smaller number of interunit linkages, and the aromatic structures are therefore connected directly to each other, resulting in a higher aromatic density. ${ }^{7}$ The EL3-4 and SL3-4 fractions, having a higher molecular weight, contain a larger number of $\beta$-O-4 bonds (Fig. $8 \mathrm{a}$ and $\mathrm{b}$ ). In the high- $M_{\mathrm{w}}$ fractions, aromatic moieties are separated by aliphatic side chains, resulting in a lower aromatic density. In the case of the SL1-4 and EL1-4 fractions, the size of LNPs increases in proportion to the lignin concentration in the initial solution (e.g. from ca. 200 to $c a .500 \mathrm{~nm}$ for the EL1 fraction). The differences in NP size can be explained by the greater degree of intermolecular $\pi-\pi$ stacking in the low- $M_{\mathrm{w}}$ SL1-2 and EL1-2 fractions, than in the high- $M_{\mathrm{w}}$ SL3-4 and EL3-4 fractions and corresponding LNPs, where intramolecular stacking dominates.

The LNPs obtained from spruce lignin were smaller than the LNPs obtained from eucalyptus lignin. At the same time, spruce lignin fractions had a higher content of carbohydrates than the eucalyptus fractions (Tables S2 and S3†). The pres- ence of carbohydrates may affect the mechanism of formation of LNPs, hindering the ability of lignin units to form noncovalent bonds with each other, and that is why we see this correlation. The slight trend deviation for the LNPs obtained from the EL4 and SL4 fractions, which were larger than the LNPs from the EL3 and SL3 fractions, could be due to the low content of carbohydrates observed in the EL4 and SL4 fractions.

\section{The relationship between the size of LNPs of the S/G content in the lignin fraction}

Both SL1 and EL1 fractions are characterized by a high content of phenolic units that play the role of "active sites" in the initial formation and growth of nanoparticles. The LNPs prepared from these fractions were larger than the LNPs obtained from the other fractions. The eucalyptus kraft lignin fractions consist mainly of syringyl units (60-70\%), and the number of these S-units decreased from the low to high $M_{\mathrm{w}}$ fractions simultaneously with an increasing number of guaiacyl units (G-units), as shown in Fig. S7 and Table S4.† The softwood lignin consisted mostly of G-units, and the number of these units was almost constant over all the fractions $(\sim 83 \pm 2 \%)$. As reported by Zhao, ${ }^{43}$ the energy of non-covalent $\pi-\pi$ interactions between G-units is higher than that between S-units. This results in a stronger bonding between softwood lignin macromolecules and a denser packing of lignin molecules during the formation of nanoparticles and thus smaller LNPs than these from eucalyptus lignin.

\section{The mechanism of formation of LNP's with regard to lignin structure}

The self-assembly of the polymers is influenced by the hydrophilic and hydrophobic interactions between the macromolecules. The hydrophobic interactions can be weakened by the introduction of charged hydrophilic groups that can form hydrogen bonds with water, and this means that the chemical structure of the lignin affects the formation of LNPs.

DLS, TEM, and SEM studies indicate that increasing the lignin concentration from 0.1 to $4 \mathrm{mg} \mathrm{m}^{-1}$ in the EL1-2 and
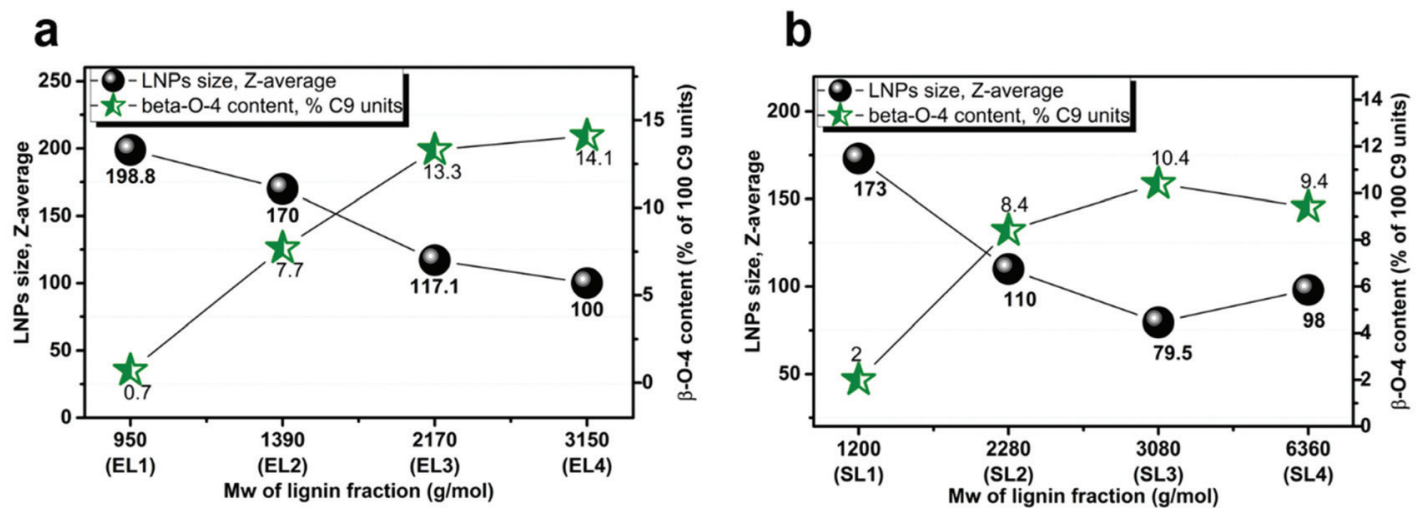

Fig. 8 LNP size, the content of $\beta-O-4$ bonds (\% of 100 C9 units) in the corresponding eucalyptus (a) and spruce (b) lignin fractions vs. $M_{w}$ of lignin fraction. 
SL1-2 fractions doesn't affect the LNP size. This contradicts the previous suggestion that LNP growth follows a nucleation growth mechanism ${ }^{20}$ where the LNP size increases in proportion to the concentration, and a refined mechanism of formation of LNPs from low- $M_{\mathrm{w}}$ lignins is here proposed.

The formation of LNPs with a core-shell structure reflects an amphiphilic property of lignin molecules acting as surfactants. These surfactant properties of SL/EL1-2 fractions are indicated by the fact that they foam during stirring when LNPS are formed when we assume that LNPs are formed as micelles due to lignin self-assembly. The presence of low-density hollow structures in the middle of LNPs, revealed by TEM (Fig. S5 $\dagger$ ) corroborates this micellar mechanism of LNP formation. The formation of doughnut-shaped structures for LNPs from EL1-2 fractions at concentrations between 0.1 and $4.0 \mathrm{mg} \mathrm{ml} \mathrm{m}^{-1}$ can also be explained by micelle formation in acetone/water mixtures. This concentration range probably lies in the post-critical micelle concentration (CMC) region. The formation of spherical LNPs was observed at a water content below $0.2 \%,{ }^{44}$ and this suggests a possible CMC threshold for LNPs. With the SL/EL1-2 fractions at initial lignin concentrations greater than $4 \mathrm{mg} \mathrm{ml}^{-1}$, some structural rearrangements in the system occurred, leading to a significant increase (almost double) in the LNP size. This agrees with PDI data for the LNPs (Fig. 3 and Fig. S3†), where the optimum initial lignin concentration range was between 2 and $4 \mathrm{mg} \mathrm{ml}^{-1}$.

The hypothesis that micelles are formed in lignin solutions, can explain the differences in shape between LNPs from softwood and hardwood. If the formation of LNPs goes through a micelle stage, it should depend on the geometry of the lignin molecules in the initial solution, and the molecular geometry should define packing parameters and micelle shape, ${ }^{45}$ leading to the formation not only of spherical micelles but also of tubes or vesicles ${ }^{46,47}$ during self-assembly. Softwood kraft lignin has a lower content of methoxy groups, and a more crosslinked structure $^{39}$ than hardwood lignin, where the higher amount of methoxy groups on S-units prevents the formation of $5-5^{\prime}$ linkages and reduces the tendency to form branched or crosslinked structures in solution. The softwood

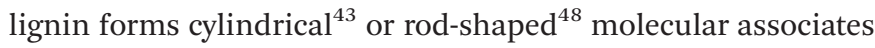
in organic solvents leading to spherical particles upon solvent exchange to minimize the contact area with the non-solvent phase. ${ }^{18}$ Eucalyptus lignin forms elongated coiled structures which assemble into more dense aggregates in organic solvents $^{48}$ and these probably lead to the formation of doughnuttype nanostructures for low- $M_{\mathrm{w}}$ eucalyptus lignin. SEM images of the LNPs synthesized at $0.1 \mathrm{mg} \mathrm{ml}^{-1}$ from EL1-2 fractions (Fig. 4, 5 and S1, $\dagger$ ) show that incompletely closed rings of lignin nanostructures were present, probably because the lignin micelles were unable to collide and close up due to the low effective lignin concentration. When the concentration of eucalyptus lignin was increased, these structures disappeared (Fig. 4 and $\mathrm{S} 1 \dagger$ ) and only spherical particles were present, suggesting that the lignin self-assembly into nano-doughnut particles probably involves the collision of tubular lignin nanostructures and their rolling up into nano-doughnuts. We believe that this micelle formation mechanism of LNP selfassembly explains the concentration-dependent LNP-formation data (DLS, Fig. 6 and 7) and the results of the microscopy studies, but the hypothesis of possible micelle formation in lignin solutions upon solvent exchange requires further investigation, including SAXS and WAXS experiments.

The structure-properties relationship between the nanoparticle morphology and the lignin chemical functionality indicates the crucial importance of selecting an appropriate starting lignin material. The application of lignin fractionation for tailoring the lignin functionality improves the linin selfassembly process into LNPs, allowing the creation of highquality nanoparticles with low PDI and tunable size and shape. The possibility of establishing a structure-properties relationship for LNPs leads to a deeper fundamental understanding of their formation and can significantly boost-up their end-use applications. The proposed approach makes closer the overarching goals of green chemistry, namely resource-efficiency, and, to our deep belief, will contribute to the safer design of the production of lignin nanomaterials.

\section{Conclusions}

Comparison of the LNPs produced using the same protocol from the lignin of two different origins (hardwood, and softwood), allowed us to link the structural differences in lignin with the size, shape, and morphology of the LNPs. The use of a green solvent fractionation step prior to the synthesis of the LNPs resulted in a range of lignin materials with tailored functionality (i.e., the contents of phenolic and aliphatic units, $M_{\mathrm{w}}$, and the number of S- and G-units). This has allowed us to create a set of high-quality LNPs with low PDI and with tunable size and shape. For both hardwood and softwood lignins, the size of the LNPs decreased with a decreasing number of phenolic hydroxyls and an increasing number of aliphatic hydroxyl units in the lignin fractions. A greater number of phenolic units seems to facilitate the interaction between lignin molecules due to stronger hydrogen bonding and $\pi-\pi$ stacking, resulting in the formation of larger LNPs. A greater number of aliphatic hydroxyls seems to reduce the intermolecular bonding between lignin molecules, leading to smaller LNPs. The stronger interaction between the G-units than between the S-units of lignin can explain the smaller average size of the spruce than of the eucalyptus LNPs. The differences in the shapes between the LNPs from spruce and eucalyptus can be explained by micelle formation and the presence of a lignin concentration threshold.

The obtained understanding allows for the selection of the most suitable lignin fractions to prepare LNPs with low PDI and tunable size and shape, thus reducing costs for the purification and further processing of LNPs. The application of the green solvents for the lignin fractionation and preparation of LNPs prevents environmental pollution by minimizing the usage of unnecessary resources, and, in our opinion, will contribute to the safer design of lignin nanomaterials. 


\section{Author contributions}

Conceptualization: Ie. Pylypchuk and O. Sevastyanova. Investigation and data curation: Ie. Pylypchuk and A. Riazanova. Funding acquisition: M. Lindström and O. Sevastyanova. Writing - original draft: Ie. Pylypchuk and O. Sevastyanova. Writing - review \& editing - all authors.

\section{Conflicts of interest}

There are no conflicts to declare.

\section{Acknowledgements}

The authors are grateful to the Knut and Alice Wallenberg Foundation for financial support through the Wallenberg Wood Science Center at KTH Royal Institute of Technology. The authors highly appreciate the help of Anthony Bristow with English gramma revision and comments on this work. Ievgen Pylypchuk acknowledges the Wood and Pulping Chemistry Research Network (WPCRN) for the financial support of his work. The authors thank the COST Action CA17128 "Establishment of a Pan- European Network on the Sustainable Valorization of Lignin" for making it possible to exchange experience with other scientists.

\section{References}

1 R. Vanholme, B. Demedts, K. Morreel, J. Ralph and W. Boerjan, Lignin biosynthesis and structure, Plant Physiol., 2010, 153(3), 895-905.

2 T. Higuchi, Lignin Biochemistry - Biosynthesis and Biodegradation, Wood Sci. Technol., 1990, 24(1), 23-63.

3 G. Gellerstedt and G. Henriksson, Lignins: major sources, structure and properties. In Monomers, polymers and composites from renewable resources, Elsevier, 2008, pp. 201224.

4 E. E. Hood, P. Nelson and R. Powell, Plant biomass conversion, Wiley Online Library, 2011.

5 C. Abbati de Assis, L. G. Greca, M. Ago, M. Y. Balakshin, H. Jameel, R. Gonzalez and O. J. Rojas, Techno-Economic Assessment, Scalability, and Applications of Aerosol Lignin Micro- and Nanoparticles, ACS Sustainable Chem. Eng., 2018, 6(9), 11853-11868.

6 C. Gioia, M. Colonna, A. Tagami, L. Medina, O. Sevastyanova, L. A. Berglund and M. Lawoko, Lignin-Based Epoxy Resins: Unravelling the Relationship between Structure and Material Properties, Biomacromolecules, 2020, 21(5), 19201928.

7 P. Olsen, M. Jawerth, M. Lawoko, M. Johansson and L. A. Berglund, Transforming technical lignins to structurally defined star-copolymers under ambient conditions, Green Chem., 2019, 21(9), 2478-2486.
8 S. Sen, S. Patil and D. S. Argyropoulos, Thermal properties of lignin in copolymers, blends, and composites: a review, Green Chem., 2015, 17(11), 4862-4887.

9 E. M. Zadeh, S. F. O'Keefe and Y. T. Kim, Utilization of Lignin in Biopolymeric Packaging Films, ACS Omega, 2018, 3(7), 7388-7398.

10 V. Aguie-Beghin, L. Foulon, P. Soto, D. Cronier, E. Corti, F. Legee, L. Cezard, B. Chabbert, M. N. Maillard, W. J. Huijgen and S. Baumberger, Use of food and packaging model matrices to investigate the antioxidant properties of biorefinery grass lignins, J. Agric. Food Chem., 2015, 63(45), 10022-10031.

11 T. M. Budnyak, A. Slabon and M. H. Sipponen, LigninInorganic Interfaces: Chemistry and Applications from Adsorbents to Catalysts and Energy Storage Materials, ChemSusChem, 2020, 13(17), 4344-4355.

12 A. M. Puziy, O. I. Poddubnaya and O. Sevastyanova, Carbon materials from technical lignins: Recent advances, in Lignin Chemistry, Springer, 2020, pp. 95-128.

13 T. M. Budnyak, I. V. Pylypchuk, M. E. Lindstrom and O. Sevastyanova, Electrostatic Deposition of the Oxidized Kraft Lignin onto the Surface of Aminosilicas: Thermal and Structural Characteristics of Hybrid Materials, ACS Omega, 2019, 4(27), 22530-22539.

14 C. Frangville, M. Rutkevicius, A. P. Richter, O. D. Velev, S. D. Stoyanov and V. N. Paunov, Fabrication of environmentally biodegradable lignin nanoparticles, ChemPhysChem, 2012, 13(18), 4235-4243.

15 M. H. Sipponen, H. Lange, C. Crestini, A. Henn and M. Österberg, Lignin for Nano- and Microscaled Carrier Systems: Applications, Trends, and Challenges, ChemSusChem, 2019, 12(10), 2039-2054.

16 M. Ago, S. Huan, M. Borghei, J. Raula, E. I. Kauppinen and O. J. Rojas, High-Throughput Synthesis of Lignin Particles (approximately $30 \mathrm{~nm}$ to approximately $2 \mathrm{mum}$ ) via Aerosol Flow Reactor: Size Fractionation and Utilization in Pickering Emulsions, ACS Appl. Mater. Interfaces, 2016, 8(35), 23302-23310.

17 G. N. Riviere, A. Korpi, M. H. Sipponen, T. Zou, M. A. Kostiainen and M. Osterberg, Agglomeration of Viruses by Cationic Lignin Particles for Facilitated Water Purification, ACS Sustainable Chem. Eng., 2020, 8(10), 4167-4177.

18 M. Österberg, M. H. Sipponen, B. D. Mattos and O. J. Rojas, Spherical lignin particles: a review on their sustainability and applications, Green Chem., 2020, 2712-2733.

19 P. K. Mishra and A. Ekielski, The Self-Assembly of Lignin and Its Application in Nanoparticle Synthesis: A Short Review, Nanomaterials, 2019, 9(2), 1-15.

20 M. H. Sipponen, H. Lange, M. Ago and C. Crestini, Understanding Lignin Aggregation Processes. A Case Study: Budesonide Entrapment and Stimuli Controlled Release from Lignin Nanoparticles, ACS Sustainable Chem. Eng., 2018, 6(7), 9342-9351.

21 A. Toledano, A. Garcia, I. Mondragon and J. Labidi, Lignin separation and fractionation by ultrafiltration, Sep. Purif. Technol., 2010, 71(1), 38-43. 
22 O. Wallberg, A. S. Jonsson and R. Wimmerstedt, Fractionation and concentration of kraft black liquor lignin with ultrafiltration, Desalination, 2003, 154(2), 187-199.

23 S. Aminzadeh, M. Lauberts, G. Dobele, J. Ponomarenko, T. Mattsson, M. E. Lindstrom and O. Sevastyanova, Membrane filtration of kraft lignin: Structural charactristics and antioxidant activity of the low-molecular-weight fraction, Ind. Crops Prod., 2018, 112, 200-209.

24 O. Sevastyanova, M. Helander, S. Chowdhury, H. Lange, H. Wedin, L. M. Zhang, M. Ek, J. F. Kadla, C. Crestini and M. E. Lindstrom, Tailoring the Molecular and ThermoMechanical Properties of Kraft Lignin by Ultrafiltration, J. Appl. Polym. Sci., 2014, 131(18), 9505-9515.

25 W. Z. Zhu, G. Westman and H. Theliander, Investigation and Characterization of Lignin Precipitation in the LignoBoost Process, J. Wood Chem. Technol., 2014, 34(2), 77-97.

26 W. Z. Zhu and H. Theliander, Precipitation of Lignin from Softwood Black Liquor: An Investigation of the Equilibrium and Molecular Properties of Lignin, BioResources, 2015, 10(1), 1696-1714.

27 A. Duval, F. Vilaplana, C. Crestini and M. Lawoko, Solvent screening for the fractionation of industrial kraft lignin, Holzforschung, 2016, 70(1), 11-20.

28 M. Helander, H. Theliander, M. Lawoko, G. Henriksson, L. M. Zhang and M. E. Lindstrom, Fractionation of Technical Lignin: Molecular Mass and pH Effects, BioResources, 2013, 8(2), 2270-2282.

29 M. S. Ma, L. Dai, J. K. Xu, Z. Liu and Y. H. Ni, A simple and effective approach to fabricate lignin nanoparticles with tunable sizes based on lignin fractionation, Green Chem., 2020, 22(6), 2011-2017.

30 Z. H. Liu, N. J. Hao, S. Shinde, M. L. Olson, S. Bhagia, J. R. Dunlap, K. C. Kao, X. F. Kang, A. J. Ragauskas and J. S. Yuan, Codesign of Combinatorial Organosolv Pretreatment (COP) and Lignin Nanoparticles (LNPs) in Biorefineries, ACS Sustainable Chem. Eng., 2019, 7(2), 26342647.

31 Z. H. Liu, N. J. Hao, S. Shinde, Y. Q. Pu, X. F. Kang, A. J. Ragauskas and J. S. Yuan, Defining lignin nanoparticle properties through tailored lignin reactivity by sequential organosolv fragmentation approach (SOFA), Green Chem., 2019, 21(2), 245-260.

32 M. Ma, L. Dai, J. Xu, Z. Liu and Y. Ni, A simple and effective approach to fabricate lignin nanoparticles with tunable sizes based on lignin fractionation, Green Chem., 2020, 22(6), 2011-2017.

33 T. Pang, G. Wang, H. Sun, L. Wang, Q. Liu, W. Sui, A. M. Parvez and C. Si, Engineering, Lignin Fractionation for Reduced Heterogeneity in Self-Assembly Nanosizing: Toward Targeted Preparation of Uniform Lignin Nanoparticles with Small Size, ACS Sustainable Chem. Eng., 2020, 8(24), 9174-9183.

34 B. Wang, D. Sun, H.-M. Wang, T.-Q. Yuan and R.-C. Sun, Engineering, Green and facile preparation of regular lignin nanoparticles with high yield and their natural broad-spec- trum sunscreens, ACS Sustainable Chem. Eng., 2018, 7(2), 2658-2666.

35 J. D. Zwilling, X. Jiang, F. Zambrano, R. A. Venditti, H. Jameel, O. D. Velev, O. J. Rojas and R. Gonzalez, Understanding lignin micro-and nanoparticle nucleation and growth in aqueous suspensions by solvent fractionation, Green. Chem., 2021, 23(2), 1001-1012.

36 M. Osterberg, M. H. Sipponen, B. D. Mattos and O. J. Rojas, Spherical lignin particles: a review on their sustainability and applications, Green Chem., 2020, 22(9), 2712-2733.

37 F. Q. Xiong, Y. M. Han, S. Q. Wang, G. Y. Li, T. F. Qin, Y. Chen and F. X. Chu, Preparation and formation mechanism of size-controlled lignin nanospheres by self-assembly, Ind. Crops Prod., 2017, 100, 146-152.

38 M. Lievonen, J. J. Valle-Delgado, M. L. Mattinen, E. L. Hult, K. Lintinen, M. A. Kostiainen, A. Paananen, G. R. Szilvay, H. Setala and M. Osterberg, A simple process for lignin nanoparticle preparation, Green Chem., 2016, 18(5), 14161422.

39 A. Tagami, C. Gioia, M. Lauberts, T. Budnyak, R. Moriana, M. E. Lindstrom and O. Sevastyanova, Solvent fractionation of softwood and hardwood kraft lignins for more efficient uses: Compositional, structural, thermal, antioxidant and adsorption properties, Ind. Crops Prod., 2019, 129, 123-134.

40 I. V. Pylypchuk, P. A. Lindén, M. E. Lindström and O. Sevastyanova, New Insight into the Surface Structure of Lignin Nanoparticles Revealed by $1 \mathrm{H}$ Liquid-State NMR Spectroscopy, ACS Sustainable Chem. Eng., 2020, 8(36), 13805-13812.

41 N. Giummarella, P. A. Linden, D. Areskogh and M. Lawoko, Fractional Profiling of Kraft Lignin Structure: Unravelling Insights on Lignin Reaction Mechanisms, ACS Sustainable Chem. Eng., 2020, 8(2), 1112-1120.

42 N. Giummarella, I. V. Pylypchuk, O. Sevastyanova and M. Lawoko, New Structures in Eucalyptus Kraft Lignin with Complex Mechanistic Implications, ACS Sustainable Chem. Eng., 2020, 8(29), 10983-10994.

43 W. Zhao, L.-P. Xiao, G. Song, R.-C. Sun, L. He, S. Singh, B. A. Simmons and G. Cheng, From lignin subunits to aggregates: insights into lignin solubilization, Green Chem., 2017, 19(14), 3272-3281.

44 J. Wang, Y. Qian, L. Li and X. Qiu, Atomic Force Microscopy and Molecular Dynamics Simulations for Study of Lignin Solution Self-Assembly Mechanisms in OrganicAqueous Solvent Mixtures, ChemSusChem, 2020, 13(17), 4420-4427.

45 J. N. Israelachvili, D. J. Mitchell and B. W. Ninham, Faraday Transactions 2: Molecular; Physics, C., Theory of selfassembly of hydrocarbon amphiphiles into micelles and bilayers, J. Chem. Soc., Faraday Trans. 2, 1976, 72, 1525-1568.

46 R. S. Seoudi and A. Mechler, Design Principles of Peptide Based Self-Assembled Nanomaterials, in Peptides and Peptide-based Biomaterials and their Biomedical Applications, ed. A. Sunna, A. Care and P. L. Bergquist, Springer International Publishing, Cham, 2017, pp. 51-94. 
47 I. S. Park, Y. R. Yoon, M. Jung, K. Kim, S. Park, S. Shin, Y. B. Lim and M. Lee, Designer nanorings with functional cavities from self-assembling beta-sheet peptides, Chem. Asian J., 2011, 6(2), 452-458.
48 D. R. Ratnaweera, D. Saha, S. V. Pingali, N. Labbe, A. K. Naskar and M. Dadmun, The impact of lignin source on its self-assembly in solution, $R S C A d v$., 2015, 5(82), 67258-67266. 